\title{
The Effect of Rapid Cooling on the Corrosion Resistance of As-Cast Aluminium Alloy 5052
}

\author{
Zbigniew Szklarz ${ }^{\mathrm{a}, *}$, Halina Krawiec ${ }^{\mathrm{a}}$, Łukasz Rogal ${ }^{\mathrm{b}}$ \\ ${ }^{a}$ AGH University of Science and Technology, Faculty of Foundry Engineering, Reymonta 23, 30-059 Krakow \\ bInstitute of Metallurgy and Material Science, Reymonta 25, 30-059 Krakow \\ *e-mail: zszklarz@agh.edu.pl
}

Received: 18 May 2017/Accepted: 7 July 2017/Published online: 28 July 2017

This article is published with open access at AGH University of Science and Technology Press

\begin{abstract}
The effect of rapid cooling by the vacuum suction casting method (VSC) on the microstructure and electrochemical response of the as-cast 5052 aluminium alloy is presented. The VSC method allowed us to obtain massive samples with a very high cooling rate $\left(10^{2}-10^{3}\right){ }^{\circ} \mathrm{C} / \mathrm{s}$. The microstructure of the quick-cooled sample (QC) has been significantly changed. Finer grains and more-homogeneous intermetallic phase distribution has been observed. Corrosion potential (OCP) and polarization measurements (LSV) revealed a higher activity of the QC alloy than ingot (IN), which leads to a denser and thicker corrosion-product formation on the surface. Electrochemical Impedance Spectroscopy (EIS) indicates higher resistance values, which suggests a greater thickness of the corrosion products.
\end{abstract}

\section{Keywords:}

aluminium alloys, cooling rate, EIS, passive films, pitting corrosion

\section{INTRODUCTION}

Aluminium alloys are widely used in many branches of industry because of their relatively low weight and high mechanical properties $[1,2]$. For example, AlMg alloys have many advantages, like quite-high mechanical properties (especially after work hardening), good weldability, and very high corrosion resistance as compared to other $\mathrm{Al}$ alloys. The requirements for construction elements are high; thus, corrosion behavior is also very important factor. Many problems of the corrosion processes in aluminum alloys are related to local processes like pitting [3]. Susceptibility to a local corrosion attack is due to the heterogeneous microstructure containing intermetallic phases and precipitates that are usually present at the grain boundaries. It has been shown in several studies that the changes observed in the chemical composition between the matrix and precipitates are the reason for the differences in the electrochemical potential distribution on the surface in high-conductivity environments. This promotes galvanic cells formation, which leads to local current flows and corrosion processes [4]. It has been revealed that some particles that are nobler than the matrix may act as cathodes, whereas particles that are less noble act as anodes [5-7]. In aluminium alloys, the cathodic character of the intermetallic phases is usually observed. For example, in AlMg alloys, Fe impurities cause an $\mathrm{Al}_{3} \mathrm{Fe}$ intermetallic phase formation, which is more noble than the surrounding matrix [8]. This is the reason for the anodic dissolution of the adjacent matrix [9]. A strongly dissolved matrix (precipitates are usually present in these sites) is the reason of decreasing mechanical properties especially at the grain boundaries. Thus, the microstructure of a given alloy has a strong influence on corrosion behavior.

The cooling rate affects the microstructure and causes the microstructure to be finer and more homogeneous. A finer and homogeneous microstructure has higher mechanical factors as well as better corrosion resistance, as confirmed by Dorin et al. [10] with double AlFe alloys. It has also been proven that higher cooling rates may play a key role in improving the corrosion resistance of $\mathrm{Al}$ alloys. It has been investigated in AlCuMg alloys that rapid cooling may inhibit the appearance of Fe-rich phases (or make them finer) [11]. Thus, it was interesting to study this effect in other aluminum alloy like AlMg.

In this paper, the rapid-cooling process (using the vacuum suction casting technique - VSC) influence on the microstructure and electrochemical response of the 5052 aluminium alloy has been described. The VSC method allows us to receive a massive sample of any alloy with a very high cooling rate, which significantly affects the state of the microstructure and properties of a given alloy (as was studied for aluminium and other metallic alloys) [12-14].

\section{EXPERIMENTAL}

\subsection{Material preparation}

Our experiments were performed on the AlMg2 alloy (5052), which is dedicated to work hardening and shows relatively high corrosion resistance. 
Two types of samples were prepared from the alloy: (1) a sample marked as IN cut from the inner part of the ingot with a diameter of $25 \mathrm{~cm}$; and (2) a quick-cooled sample (QC) obtained by sucking melted alloy to a cold copper mold. This method is called the vacuum suction casting method, and it allows us to obtain massive samples with very high cooling rates. In this case, the sample from the ingot was remelted by using an induction coil and sucked into the cold copper mold by use of a vacuum pump. In this manner, a massive quick-cooled sample with dimensions of $3 \times 2 \times 0.35 \mathrm{~cm}$ was prepared (Fig. 1). The cooling rate has been estimated at $\left(10^{2}-10^{3}\right){ }^{\circ} \mathrm{C} / \mathrm{s}$.

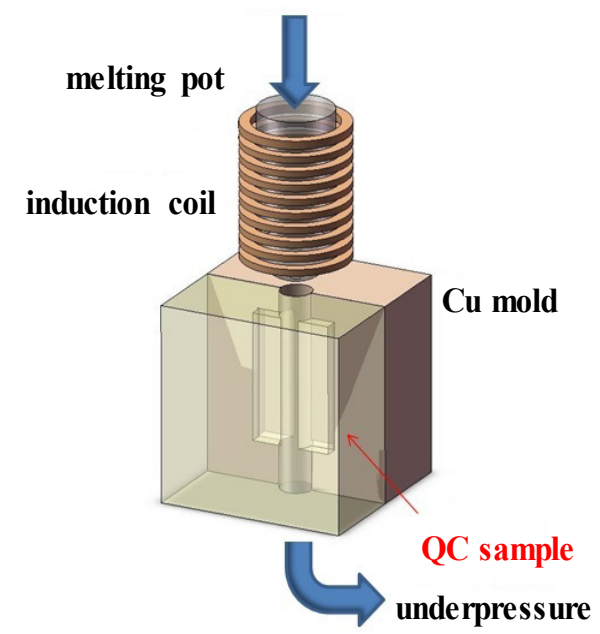

Fig. 1. Schematic drawing of vacuum suction casting process that was used to obtain quick-cooled sample (QC)

Before the microstructure recognition and electrochemical studies, both the IN and QC samples (each with a surface area of about $0.5 \mathrm{~cm}^{2}$ ) were mechanically polished using diamond pastes and smoothed with a colloidal silica suspension. The samples were then cleaned in ethanol and dried in air.

\subsection{Surface observations and analysis}

LM and SEM/EDS techniques were used to conduct observations of the surface and analyze the chemical composition of both the IN and OU specimens. An LM (Nikon Eclipse L100 microscope) was used for the optical observations of the surface of the specimens. The SEM/EDS technique (FEI SEM XL30) was used to observe the surface with high resolution and analyze the local chemical element composition.

\subsection{Electrochemical studies}

Corrosion behavior studies were performed by using the classical electrochemical three-electrode system [15]. In this system, the platinum plate was used as a counter electrode, $\mathrm{Ag} / \mathrm{AgCl}(3 \mathrm{M} \mathrm{KCl})$ as a reference electrode, and the previously described aluminium alloy specimens act as working electrodes. The working surface of the specimens used for these measurements was about $0.5 \mathrm{~cm}^{2}$.
As an environment, a $0.1 \mathrm{M} \mathrm{NaCl}$ water solution was used, and the measurements were conducted at room temperature.

To investigate the corrosion behavior of the IN and QC samples, linear sweep voltammetry (LSV), corrosion potential - open circuit potential measurements (OCP), and electrochemical impedance spectroscopy (EIS) were employed.

The LSV method is based on recording the current density response from the tested material according to the linear potential growth. This allows us to obtain polarization curves that are characteristic for a given material under the given conditions.

The OCP method is a simple measurement of the electrode potential versus the reference electrode.

The principle of EIS measurement consists of applying a variable signal (usually sinusoidal) to the sample with a given instantaneous frequency and amplitude. The current response and phase shift are recorded. The potential and current values ratio is an impedance that provides information about the conditions at the electrode/electrolyte interface.

\section{RESULTS AND DISCUSSION}

\subsection{Microstructure of IN and QC samples}

In Figure 2, the optical microscope images are posted of the surface of the samples cut from the ingot (a) and the QC sample obtained by the vacuum-suction technique (b). Both the IN and QC samples were mechanically polished and etched in a $2 \% \mathrm{HF}$ water solution.

a)

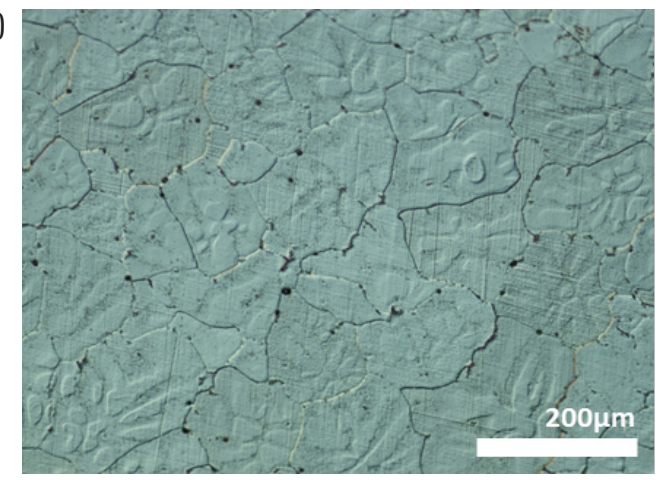

b)

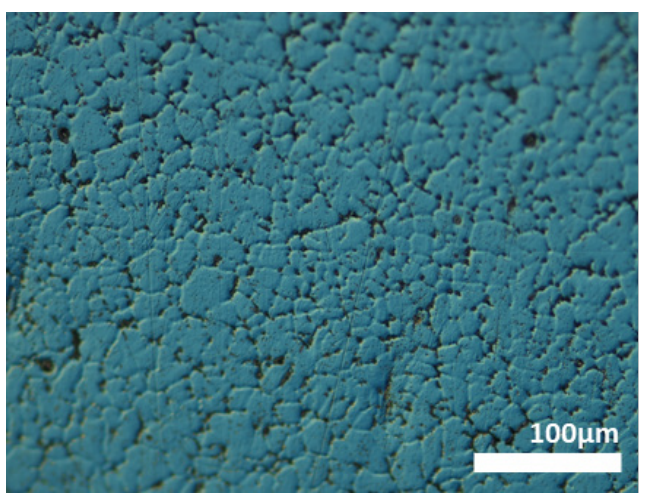

Fig. 2. Optical images of surface of IN (a) and QC (b) samples after etching in $2 \% \mathrm{HF}$ water solution in order to reveal grain boundaries 
First of all, a large change in the grain size can be observed after etching. The structure of the QC sample is much finer. Moreover, for the QC specimen, the microstructure transformed from equal-axes grains to dendritic (Fig. 2). Also, the chemical element distribution has been modified after the rapid-cooling process (as revealed by SEM/EDS analysis) (Fig. 3).

a)

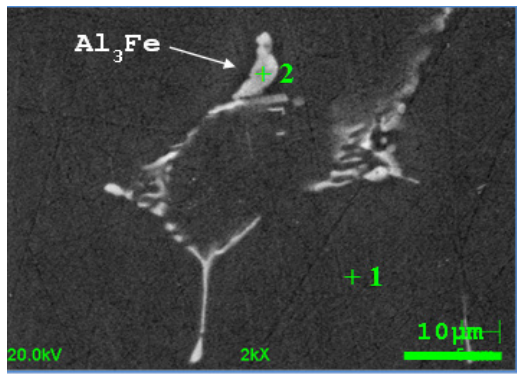

b)

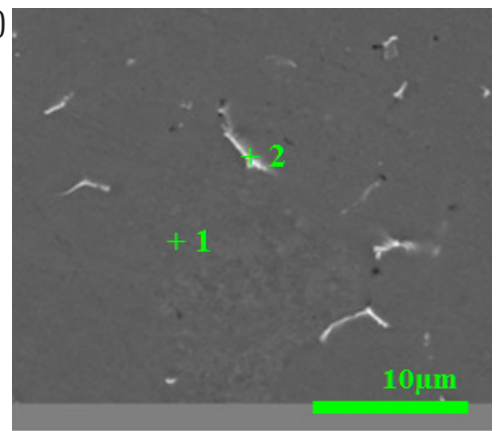

Fig. 3. FEM images of surface of IN (a) and QC (b) samples after mechanical polishing

It can be seen that, for the ingot (Fig. 3a), the microstructure is heterogeneous and coarse, which is caused by the slow solidification of the alloy in such a big casting (as mentioned, the ingot is $25 \mathrm{~cm}$ in diameter). The matrix is composed of 98 at.\% of $\mathrm{Al}$ and about 2 at.\% of $\mathrm{Mg}$ (Tab. 1). There are long and narrow intermetallic phases observed that are enriched in Fe. SEM/EDS analysis suggests that it is the $\mathrm{Al}_{3} \mathrm{Fe}$ phase that often occurs in aluminium alloys.

The rapid-cooling process results in changes to the chemical element distribution. The matrix is enriched in the $\mathrm{Mg}$ and Fe. The precipitates are much smaller-enriched in Mg, and they contain lower amounts of Fe (Tab. 1).

Table 1

Chemical element composition analysis obtained from sites indicated in Figure 3

\begin{tabular}{ccccc}
\hline \multirow{2}{*}{$\begin{array}{c}\text { Element } \\
\text { at. \% }\end{array}$} & \multicolumn{2}{c}{ Figure 3a } & \multicolumn{2}{c}{ Figure 3b } \\
\cline { 2 - 5 } & Point +1 & Point +2 & Point +1 & Point +2 \\
\hline $\mathrm{Al}$ & 97.4 & 86.5 & 97.3 & 91.5 \\
\hline $\mathrm{Mg}$ & 2.2 & 1.2 & 2.6 & 4.7 \\
\hline $\mathrm{Fe}$ & 0.03 & 9.5 & 0.1 & 3.8 \\
\hline
\end{tabular}

\subsection{Electrochemical investigations}

Differences in the grain size, chemical composition, and precipitate distribution observed between both the IN and QC samples may have an impact on the corrosion behavior of the 5052 alloy in a chloride environment; thus, electrochemical studies in chlorides have been performed.
First, the polarization curves have been plotted with a $1 \mathrm{mV} / \mathrm{s}$ scan rate (Fig. 4a). As it is seen for the ingot (IN; black curve) and quick-cooled (QC; red curve) specimens, a sharp increase in the anodic current density is observed in the anodic domain as soon as the corrosion potential is reached (no passive range). Both the IN and QC samples undergo pitting corrosion, which has been proven by the optical images (Figs. $4 \mathrm{~b}$ and $4 \mathrm{c}$ ). However, the pitting potential registered for the QC specimen $\left(E_{p i t}\right)$ is about $-0.6 \mathrm{~V}$ vs. $\mathrm{Ag} / \mathrm{AgCl}$ ) is higher when compared to IN (pitting starts immediately after corrosion potential is achieved); this indicates a slightly better resistance against pitting for the QC alloy. Moreover, the structural etching is observed in the case of IN (while not observed for QC). The corrosion potential $\left(E_{\text {corr }}\right)$ is lower for the QC specimen $(-830 \mathrm{mV}$ vs. $\mathrm{Ag} / \mathrm{AgCl})$ than for IN $(-770 \mathrm{mV}$ vs. $\mathrm{Ag} / \mathrm{AgCl})$, which suggests higher electrochemical activity of the alloy after rapid cooling.

a)

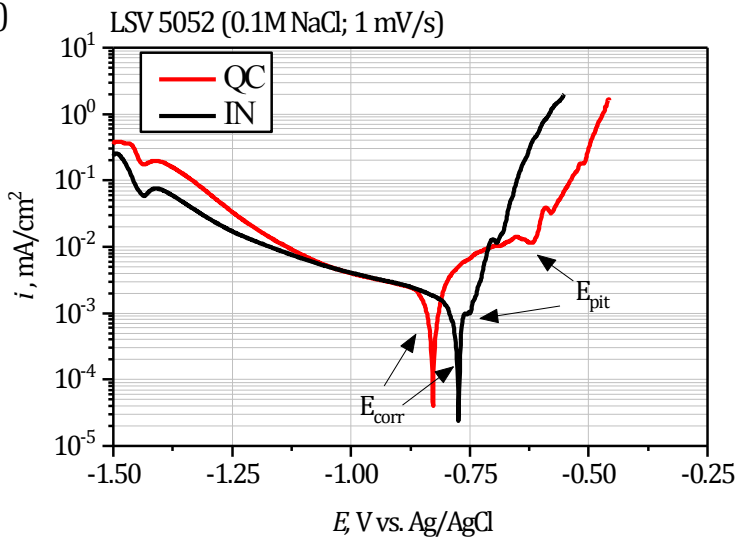

b)

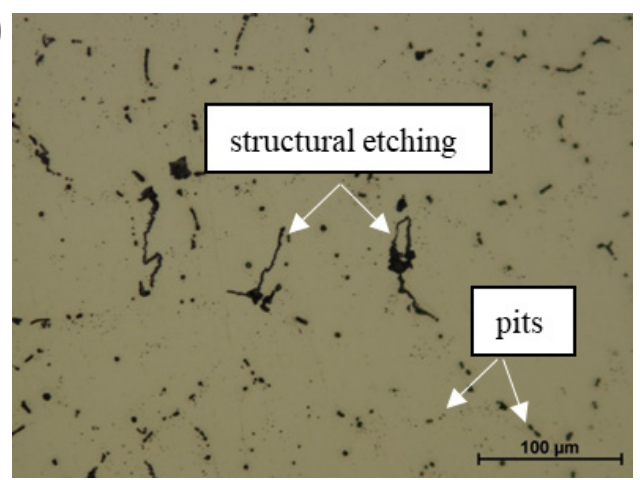

c)

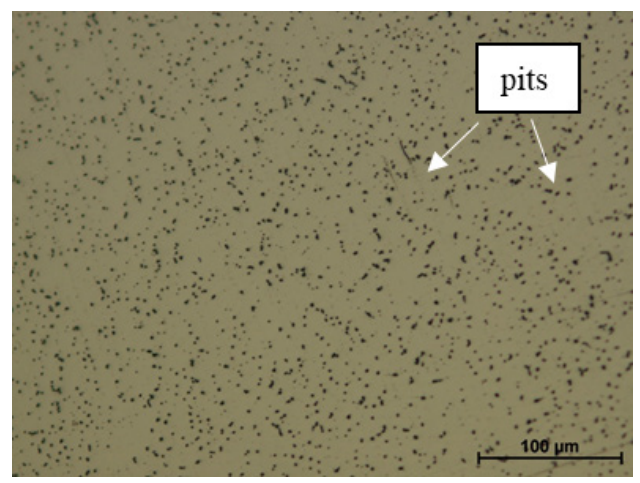

Fig. 4. Polarization curves ( $1 \mathrm{mV} / \mathrm{s}$ scan rate) obtained for IN (black curve) and QC (red curve) - (a); optical images of IN and QC samples respectively, after polarization tests - (b) and (c) 
In order to verify the influence of time on the corrosion behavior of the 5052 aluminium alloy after the rapidcooling process, the open circuit potential (OCP) has been registered after 5,24 , and $48 \mathrm{~h}$ of immersion in $0.1 \mathrm{M} \mathrm{NaCl}$ (Fig. 5). As can be seen, the corrosion potential decreased for both IN and QC specimens during $48 \mathrm{~h}$ of contact with a $0.1 \mathrm{M} \mathrm{NaCl}$ environment. This indicates that there are no passive-layer-forming processes (no passivation), which correlates well with the polarization measurements (Fig. 4). Moreover, the corrosion potential is lower for the QC specimen, which has been confirmed by previous LSV measurements.

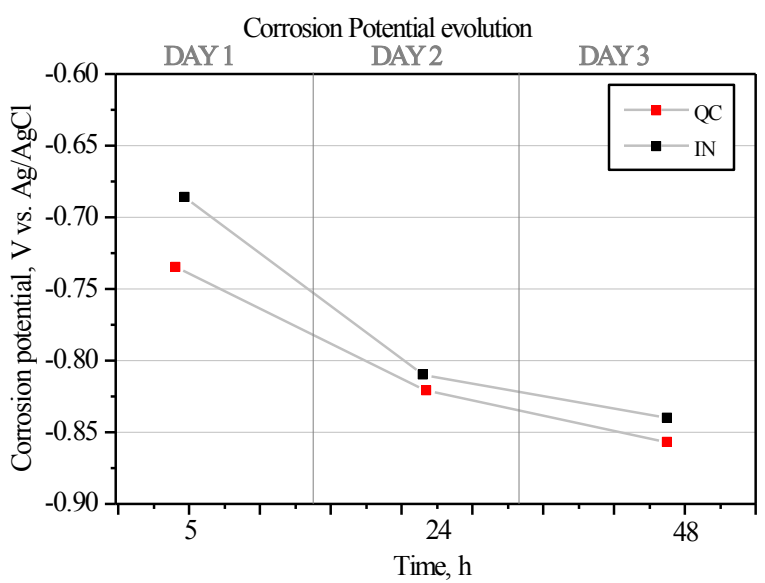

Fig. 5. Corrosion potential evolution during $48 \mathrm{~h}$ immersion test in chlorides

Impedance measurements were conducted at the corrosion potential (OCP). These measurements were made using a sinusoidal signal with an amplitude of $10 \mathrm{mV}$ in a range of frequencies from $50 \mathrm{kHz}$ to $10 \mathrm{mHz}$. EIS studies were performed after $5 \mathrm{~h}, 24 \mathrm{~h}$, and $48 \mathrm{~h}$ of immersion in a $0.1 \mathrm{M} \mathrm{NaCl}$ water solution in order to observe the kinetics of the corrosion processes.

The EIS diagrams obtained for the ingot (Fig. 6a) and quick-cooled sample (Fig. 6b) shows two time constants (two loops are visible). This infers two electrochemical processes at the electrodes/electrolyte interface and is related to the nonhomogeneous surface where the anodic matrix and cathodic precipitates occur.

It is clearly seen that, for the QC sample, the impedance loops are larger in diameter (resistances are higher) for each $5 \mathrm{~h}, 24 \mathrm{~h}$, and $48 \mathrm{~h}$ of immersion when compared to the IN sample. This suggests a higher corrosion-product resistance in the 5052 alloy after the vacuum suction casting method. This may be related to the higher activity and higher surface density of the precipitates that are present in the QC sample. This leads to the formation of a thicker corrosion-product layer covering the specimen surface.

The impedance results confirm the earlier measurements of the polarization curves obtained for these electrodes (Fig. 4). The sample after processing by VSC (QC) has a higher cathodic current density and nonlinear ("shredded") anodic current, which may suggest difficulties in the dissolving process of the material - associated with the presence of the thicker/more resistant corrosion-product layer.

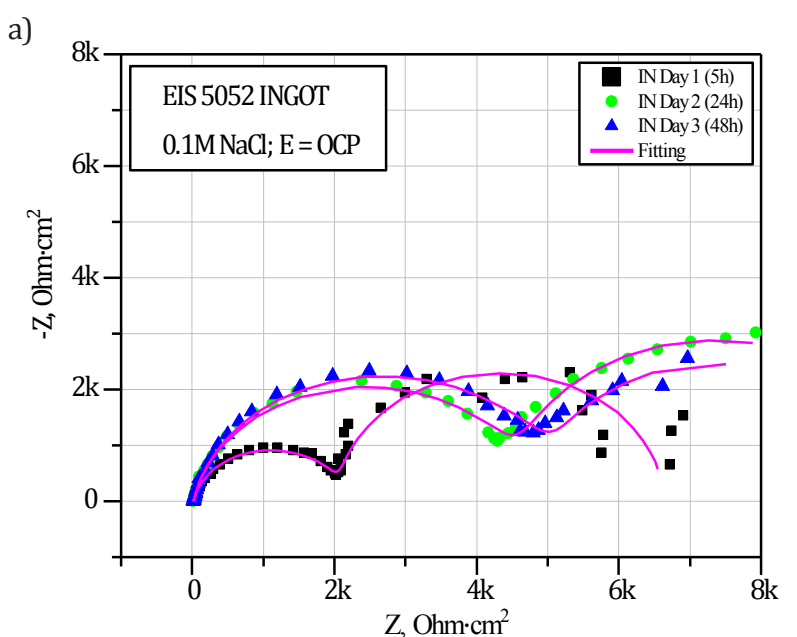

b)

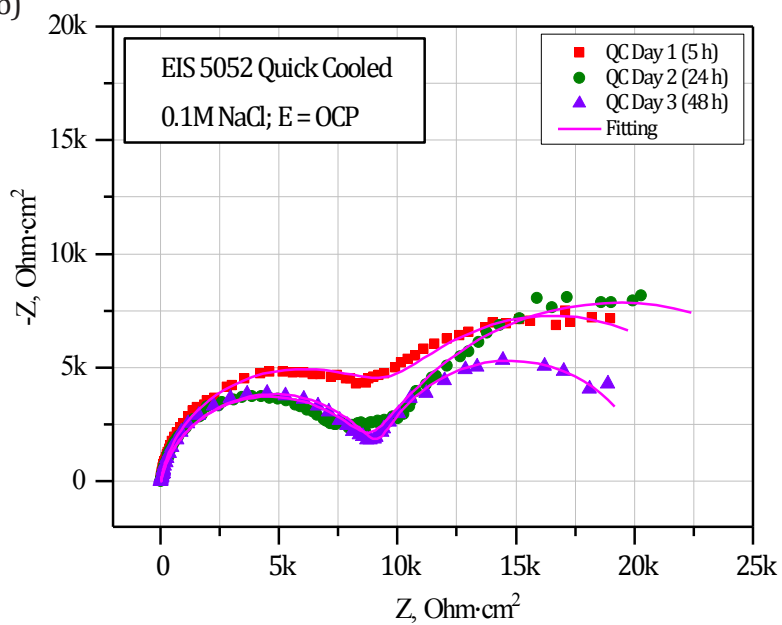

Fig. 6. EIS results obtained for IN (a) and QC (b) specimens during $48 \mathrm{~h}$ immersion test showing electrochemical behavior at electrolyte/electrode interface

\section{CONCLUSIONS}

The Vacuum Suction Casting process allowed us to obtain massive samples of the 5052 aluminium alloy with a much-finer microstructure when compared to the as- cast sample.

Electrochemical measurements (OCP, LSV) revealed a higher activity in the alloy after rapid cooling (QC specimen). The higher electrochemical activity causes moreintensive electrochemical reactions, which leads to the higher density and thicker corrosion-product-layer formation on the QC specimen surface. The higher density and thicker corrosion-product layer that covers the surface of the QC alloy has been confirmed by the EIS method (higher resistances values). Moreover, EIS measurements indicate that the thick corrosion-product layer formed in $0.1 \mathrm{M} \mathrm{NaCl}$ after rapid cooling makes the 5052 alloy more resistant to chlorides.

\section{Acknowledgements}

The authors gratefully acknowledge the financial support by the Polish Ministry of Higher Education (Grant no. 15.11.170.576). 


\section{REFERENCES}

[1] ASM Handbook Volume 2: Properties and Selection: Nonferrous Alloys and Special-Purpose Materials (1990). Materials Park: ASM International.

[2] Brown J.R. (1999). Foseco Non-Ferrous Foundryman's Handbook. Butterworth-Heinemann.

[3] Hollingsworth E.H., Hunsicker H.Y. (1987). Corrosion of Aluminium and Aluminium Alloys. Vol. 13, ASM Handbook. Materials Park: ASM International.

[4] Schweitzer P.A. (2009). Fundamentals of Corrosion, Mechanisms, Causes, and Preventative Methods. Boca Raton: CRC Press.

[5] Birbilis N.R., Buchheit G. (2005). Electrochemical characteristics of intermetallic phases in aluminum alloys. Journal of The Electrochemical Society, 152(4), B140-B151.

[6] Suter T., Alkire R.C. (2001). Microelectrochemical Studies of Pit Initiation at Single Inclusions in Al 2024-T3. Journal of The Electrochemical Society, 148(1), B36-B42.

[7] Krawiec H., Vignal V., Szklarz Z. (2008). Local electrochemical studies of the microstructural corrosion of AlCu4Mg1 as-cast aluminium alloy and influence of applied strain. Journal of Solid State Electrochemistry, 13, 1181-1200.

[8] Krawiec H., Szklarz Z., Vignal V. (2012). Influence of applied strain on the microstructural corrosion of AlMg2 as-cast aluminium alloy in sodium chloride solution. Corrosion Science, 65, 387-396.
[9] Handbook of Aluminium. Vol. 2, Corrosion of Aluminum and Its Alloys. Chapter 13 (2003).

[10] Dorin T., Stanford N., Birbilis N., Gupta R.K. (2015). Influence of cooling rate on the microstructure and corrosion behavior of Al-Fe alloys. Corrosion Science, 100, 396-403.

[11] Liu Y., Liu M., Luo L., Wang J., Liu Ch. (2014). The solidification behavior of AA2618 aluminum alloy and the influence of cooling rate. Materials, 7(12), 7875-7890.

[12] Das N., Sengupta P., Abraham G., Arya A., Kain V., Dey G.K. (2016). Development in corrosion resistance by microstructural refinement in Zr-16 SS 304 alloy using suction casting technique. Materials Research Bulletin, 80, 295-302.

[13] Sheng-yong Li, De-jiang Li, Xiao-qui Zeng, Wen-jiang Ding. (2014). Microstructure and mechanical properties of Mg-6Gd-3Y-0.5Zr alloy processed by high-vacuum die-casting. Transactions of Nonferrous Metals Society of China, 24(12), 3769-3776.

[14] Sheng L.Y., Zhang W., Guo J.T., Zhou L.Z., Ye H.Q. (2009). Microstructure evolution and mechanical properties' improvement of NiAl-Cr(Mo)-Hf eutectic alloy during suction casting and subsequent HIP treatment. Intermetallics, 17(12), 1115-1119.

[15] Perez N. (2004). Electrochemistry and Corrosion Science. Boston: Kluwer Academic Publishers. 